Review

\title{
The production of valuable products and fuel from plastic waste in Africa
}

\author{
M. Opoku Amankwa ${ }^{1,3}$ (D) E. Kweinor Tetteh ${ }^{2}$ (D) G. Thabang Mohale ${ }^{1,4} \cdot$ G. Dagba ${ }^{1,3}$ (D) P. Opoku ${ }^{1,5}$ (I)
}

Received: 17 March 2021 / Accepted: 8 June 2021

Published online: 08 July 2021

(c) The Author(s) $2021 \quad$ OPEN

\begin{abstract}
Global plastic waste generation is about 300 million metric tons annually and poses crucial health and environmental problems. Africa is the second most polluted continent in the world, with over 500 shipping containers of waste being imported every month. The US Environmental Protection Agency (EPA) report suggests that about $75 \%$ of this plastic waste ends up in landfills. However, landfills management is associated with high environmental costs and loss of energy. In addition, landfill leachates end up in water bodies, are very detrimental to human health, and poison marine ecosystems. Therefore, it is imperative to explore eco-friendly techniques to transform plastic waste into valuable products in a sustainable environment. The trade-offs of using plastic waste for road construction and as a component in cementitious composites are discussed. The challenges and benefits of producing liquid fuels from plastic waste are also addressed. The recycling of plastic waste to liquid end-products was found to be a sustainable way of helping the environment with beneficial economic impact.
\end{abstract}

Keywords Biodiesel · Landfills · Plastic waste · Pyrolysis · Recycling

\section{Introduction}

Plastics production has increased to a global value of 311 million tonnes (MT) since the 1930s, with a growth rate of about $4 \%$ [1]. However, plastic usage is necessary for everyday living, and without it, modern markets and shopping can become much intricate [1, 2]. Plastics are used daily in packaging wide assorted goods, drinks, food for easier transportation, footwear, clothing, telecommunications, transport, among other things [3]. This has resulted in large-scale production with its durability, lightweight, low manufacturing costs displacing the use of unconventional materials like ceramics, metals, woods, among other things [3]. The large-scale production and proliferation of plastics have become a global concern due to their polluting effects [4]. They are primarily unrecycled and end up either in the natural environment or landfills [1]. Some of these plastics also end up in marine habitats, tourist sites, freshwater, and natural terrestrial [3]. Due to their extensive disposal level in the marine or ocean, aquatic lives have been distorted, leading to their near extinction [3]. Reports indicate that about 700 aquatic lives, including seabirds, marine animals, fishes, among other things, could

$\triangle$ M. Opoku Amankwa, amankwamark12@gmail.com; E. Kweinor Tetteh, ektetteh34@gmail.com; emmanuelk@dut.ac.za; G.Thabang Mohale, mohalegt@gmail.com; G. Dagba, gershondag@gmail.com; P. Opoku, opokumethodist@gmail.com | 'Department of Public Administration, Punjabi University, Patiala 147002, India. ${ }^{2}$ Faculty of Engineering and the Built Environment, Department of Chemical Engineering, Durban University of Technology, Steve Biko Campus Block S4 Level 1, Box 1334, Durban 4000, South Africa. ${ }^{3}$ Department of Public Administration, Punjabi University, Patiala, India. ${ }^{4}$ Department of Journalism and Mass Communication, Punjabi University, Patiala, India. ${ }^{5}$ Department of Political Science, Punjabi University, Patiala, India. 
go extinct due to their incessant injuries by plastic waste [2]. This has been attributed to the entanglement, suffocation, infection, drowning, starvation, and ingestion of plastic waste [2].

Also, the burning of plastics in landfills and various homes unabatedly has increased global anthropogenic carbon footprints [3]. Africa is now the second most polluted continent in the world, with over 500 shipping containers of waste being imported every month [3]. The data available on 33 African countries indicate that the continent had imported about 172 Mt of plastic waste and polymers between 1990 and 2017, valued at \$US 285 billion [4]. As compared to other African countries, Tunisia (7\%), Morocco (9.6\%), Algeria (11.3\%), South Africa (11.7\%), Nigeria (17\%), and Egypt (18.7\%) had the largest share of the importation [4]. In South Africa, for example, 90,000 tonnes to 250,000 tonnes of plastic entering the sea each year [3]. It is further estimated that the importation of plastics to the continent would likely double in the next five years, contributing to the rise in world's temperature significantly [4]. World's temperature is also projected to increase from 1.5 to $3^{\circ} \mathrm{C}$ with a corresponding impact on food insecurity, water supply, inequality, and poverty [5].

Although plastic waste has been a bane on the environment, humans, aquatic animals, and increasing climatic conditions, its benefits cannot be overlooked. It is essential to argue that the material is highly resistant, lightweight, versatile, and cheap [3]. Thus, it gives a valuable position in providing several environmental benefits critical in reducing food waste and maintaining food safety and quality [6]. The trade-offs between plastics and a complete ban on plastic could be intricate and lead to a negative knock-on effect on the environment [6]. It is against this backdrop that this paper explores two eco-friendly techniques to transform plastic waste into valuable products in a sustainable environment.

Extant literature has explored eco-friendly techniques to transform plastic waste into valuable products in a sustainable environment; however, there is limited literature in the African context. First, ASCE, Elsevier, Google Scholar, and Web of Science were some databases that were employed to search for peer-reviewed publications, and the researchers selected publications written in English. Some of the keywords used were'production', eco-friendly techniques', 'plastic', and 'plastic waste'. The Boolean operators including 'AND' and 'OR' were also used in the search. The timeframe of these publications was set to 2002 to 2021 to include recent papers for the publication and the relevant papers selected. The backward and forward snowballing which means using citations within publications and finding citations were also adopted.

The next section is as follows. Section 2 explores eco-friendly techniques to transform plastic waste into valuable products in a sustainable environment. Section 3 addresses the challenges and benefits of producing liquid fuels from plastic waste. Section 4 concludes the study with recommendations for future research.

\section{Eco-friendly techniques to transform waste into valuable products in a sustainable environment}

To comprehend the eco-friendly techniques to transform waste into valuable products in a sustainable environment, it is essential to understand the different plastics, waste management chain, and distribution components. This is pivotal in understanding the nature of the problem and executing the best mediations for decreasing plastic waste. Millions of plastics that can be recycled or reuse end up being improperly discarded [1]. The global production of plastics was only 2 million tonnes in the 1980s, but there has been an abysmal increase in plastic production, resulting in about 381 million tonnes of plastic production in 2015 [6]. This implies that the world has produced over 7.82 billion tonnes of plastic waste cumulatively from 1950 to 2015 [7]. In the 1980s, 100\% of the plastic waste generation was totally discarded without being incinerated or recycled [6]. As technology advanced, several methods were discovered in properly disposing of these waste products [8]. By 2015, 55\% of plastic waste was still being discarded, $25.50 \%$ incinerated, and only $19.50 \%$ recycled [6].

In Africa, the total production of plastic waste was estimated at $15.9 \mathrm{Mt}$, with 8 African countries playing critical roles in its production, with the highest productions from Nigeria (2.3 Mt), Egypt (4.0 Mt), and South Africa (9.0 Mt) [9]. For instance, South Africa began production of plastic in the 1970s and polypropylene in 1991 at an average of 120,000 t a year [10]. The average production then rose to $220,000 \mathrm{t}$ at the end of 2001 [4]. Among the widely produced plastics, polyolefins, in other words, polyvinyl chloride (PVC), polypropylene (PP), polypropylene (PP), polystyrene (PS), low-density polyethene (LPDE), and high-density polyethene (HDPE) accounts for $50 \%$ of the overall plastic production [2]. These plastics have a broad spectrum of additives, including thermal stabilisers, slip compounds, antistatic agents, lubricants pigments, heat and light stabilisers, acid scavengers, antioxidants, flame retardants, and plasticisers [4]. Some of these additives have been classified as endocrine-disrupting chemicals [EDCs, e.g. Diethylhexylphthalate (DEHP) or bisphenol A], while others have been classified as toxic [11]. Some have also been noted as persistent organic pollutants (POPs), 
including short-chain chlorinated paraffin (SCCPs); hexabromocyclododecane (HBCD); hexabromobiphenyls (HBB); flame retardants polybrominated diphenyl ethers (PBDEs); fluorinated tensides, eg. Perfluorooctanoic acid (PFOA) [4].

Polyethene (LDPE and HDPE) has contributed to $7 \mathrm{Mt}$ of waste polymers over the last decade because it is used for producing sachets [11]. For instance, in Ghana, 150,000 sachets are produced a day by larger companies, while 45,000 sachets are produced a day from small-scale sachet water companies [12]. Further, over 40 plastic manufacturing companies were set up by the close of 2006, producing approximately 26,000t of plastic [12], resulting in agricultural pollution in the country [13]. Also, in Nigeria, excessive littering in the country has been attributed to the country's excessive production of sachet water [14]. Over 60 million sachets are consumed daily, while Lagos alone accounts for 1500 sachet water factories [14] with little to no deposit return policies on the sachets produced. The current production and importation of plastic waste are likely to negatively affect the continent if recycling channels are fully adopted and operationalised.

Further, the usage time of plastic distribution includes a noteworthy test of sustainability because of the short life utilisation of these plastic applications [6]. The most widely used application of plastic is in the packaging sector, which accounts for about 146 million tonnes of plastic production and usage [7]. This suggests that a dominant fraction of plastic use has less than a month life span and mostly ends up in streams, freshwater bodies, and the marine [1]. Presently, the predominant application of plastic waste is that $30.8 \%$ are sent to the landfill, $29.7 \%$ are being recycled, and $39.5 \%$ is energy recovery [2]. Particularly in Africa, there are hardly energy or thermal recovery from plastic waste, including cement kilns and incinerators, and almost all the plastic wastes end up at the dumping sites [4]. Even though there has been a massive reduction in sending plastic waste to landfills in developed countries, the situation is far from satisfactory and even worse in most developing countries, especially Africa.

The unconventional approach of processing plastic waste at incineration and landfill sites is no longer sustainable [5]. This is due to the high emissions of toxic gases, including carbon dioxide $\left(\mathrm{CO}_{2}\right)$, into the atmosphere, thereby increasing global temperatures and climatic conditions [6]. As such, there has been intense pressure from climate change agencies like the United Nations Framework Convention for Climate Change (UNFCCC) and the Paris Agreement to find innovative ways of recycling these plastic wastes [7]. Various methods have been identified, including the conversion of polyolefin waste into a broad spectrum of valuable products lie clean fuels, naphtha (a combination of hydrocarbons), polymers, among other things. The potency of this innovative technology has the impetus to shrink the use of plastic waste globally while increasing the profits of recycling companies. The current urbanisation worldwide, especially in the global south where there is limited development, plastic waste could be used to construct roads, developing real estates, among others. This reduces the pressure on cement production, which currently also contributes to $10 \%$ of the world's atmospheric carbon print [6]. Again, waste-pickers have played pivotal roles over the years to reduce plastic waste in the environment [15]. Waste pickers are self-employed, small-scale individuals commonly found in the city's informal economy [16]. Waste is obtained for personal use or to sell to buy-back centers and/or higher-level dealers [17]. About $2 \%$ of the global population earns a living by gathering, sorting, using, and/or selling salvageable waste [15]. For instance, roughly 37,000 South Africans earn a living from picking plastic waste [17], having an impact in reducing plastic waste in the environment.

The world is faced with the rapid expansion of cities, with the most happening in the global south, especially in African countries [18]. The urbanisation of these cities into megacities is inexplicable with corresponding population explosion, and migration traffic keeps building up in those areas [19]. For example, in areas like Lagos, Mumbai, etc., several reports of massive traffic build-up sometimes last for several hours [18]. These developing megacities and urban centres are faced with huge levels of plastic pollution, with various governments failing to implement stringent measures to curb such situations [19]. In effect, there have been several reports of negative impact on the economies of these cities as well as countries [20]. Despite these challenges, the government cannot totally ban plastic due to its environmental benefits and the trade-offs between plastics and a complete ban of plastic, leading to a negative knock-on effect on the environment [6]. As such, plastic waste could be utilised to construct roads to expand road infrastructure in these centres as urbanisation is inevitable.

The application of plastic waste has also been considered in the construction of roads and road surfacing globally, especially in the global south, where road infrastructure is limited [18]. These materials are used to prevent a double tragedy of limited asphalt roads and limited resources (like sand, gravels, among others) in road construction [21]. Utilising polymer-modified bitumen to achieve better asphalt roads has also been considered for a long time [18]. Thus, while increasing the construction of roads around the world with plastic waste, the rampant use of natural materials, including sand and gravel for asphalt roads which are exhaustive, is also reduced [20]. Waste plastics of various forms have been used as modifiers in pavement materials [21]. According to statistics, three types of waste plastics were most commonly used by researchers: PET, PE, and PP [22-26]. Thus, PET, PE, and PP have been found to have excellent binding 
properties and softens when subjected to heat between 100 and $160^{\circ} \mathrm{C}[18,22]$. Extant literature indicated that the melting temperatures of PP, PET and HDPE were $135^{\circ} \mathrm{C}, 160^{\circ} \mathrm{C}$, and $165^{\circ} \mathrm{C}$, respectively [18-23]. Particularly PET absorbs some oil and releases a low molecular weight fraction ( 5 to $10 \%$ by weight) into bitumen which increases the velocity of bitumen-plastic composite (BPM) [25]. This makes it highly blendable with bitumen for the construction of roads [23]. On the other hand, heating plastic waste above $270^{\circ} \mathrm{C}$ tends to decompose, and $750^{\circ} \mathrm{C}$ tends to release noxious gases [22].

The strength of asphalt to withstand shearing deformation is measured in viscosity [21, 22]. If the viscosity is too high, the binder may struggle to flow to cover the aggregates [21]. Thus modifying and controlling the viscosity of polymerbased asphalt is also important [22]. The viscosity of virgin binders is generally increased when waste plastics are added. When HDPE and PP are added, however, viscosity reduces until the HDPE and PP concentrations exceed 2.5\% [18]. This may be demonstrated by the thixotropic effect, and the thixotropic effect of polymer modified asphalt may be attributed to the reversible structure breakdown that is typical in polymer modified bitumen multiphase systems [18]. The physical and chemical qualities of recycled materials are closely related to their properties [21]. The porous mortar covering on the floor, for example, gives Recycled Concrete Aggregates (RCAs) their high absorbency and low abrasion resistance [23]. As a result, thoroughly comprehending the physical and chemical characteristics of recycled products would aid in developing disposal procedures and the analysis of test results. When it comes to waste polymer components, the interfacial character and blend properties are also crucial. The surface state of polymers is significantly altered by electron irradiation and trans-polyoctenamer (TOR), and understanding polymers in terms of molecular structure and functional groups are important [25].

Research again shows that combining PP and BPM are less susceptible to temperatures and fatigue, improved pavement performance, and better rutting resistance when used for road construction than other forms of plastic wastes [22]. Also, bitumen could be blended with polymer-coated aggregate for better stripping value and higher Marshall Value, which is also more suitable for road construction [23]. For instance, plastic waste like thermocole, cups, films, and disposed carry bags have been used to construct about $1500 \mathrm{~km}$ of roads in Maharashtra, India, which has been able to withstand high temperatures, rain, and heavy traffic [20]. For every tonne of waste plastic used in the construction of one $\mathrm{km}$ road, it is estimated that about 3 tonnes $/ \mathrm{km}$ of carbon emissions are reduced in the atmosphere in India [20]. Also, plastic waste is being used in countries like South Africa, Ethiopia, the Netherlands, the United States, Australia, and the UK to construct roads [19]. The UK government also announced a $£ 23$ million investment in plastic roads in eight local authorities [19]. NelPlast Ghana Limited also makes pavements from plastic waste approved by the Ministry of Environment, Science, Technology, and Innovation in Ghana [18]. As depicted in Fig. 1 is a pavement block made of plastic waste in Ghana.

Urbanisation has further resulted in an unprecedented rate of housing deficit globally and, therefore, the need for affordable housing units [27]. The cause has been attributed to several factors, including; the high rising cost of housing units against income, high demand against supply, population growth, and scarcity of land, among others [28]. Plastic waste has been considered as a better alternative for the construction of housing units [29]. Most of the extant research has been conducted in most developing countries with high population growth rate [27, 29]. Population growth has become acute and quite natural in recent times, leading to urbanisation. This has pushed urban centres into sub-urban centres and mostly leading to improper settlements or slums [27]. A considerable amount of plastic waste is generated every day in these areas, having negative repercussions on municipal development [30]. The rampant growth in these urban centres has been attributed to land unavailability and huge housing costs in urban centres, thereby pushing these settlements into sub-urban areas resulting in improper settlements [30].

Fig. 1 Pavement block made of plastic waste (Source: Quartz Africa)

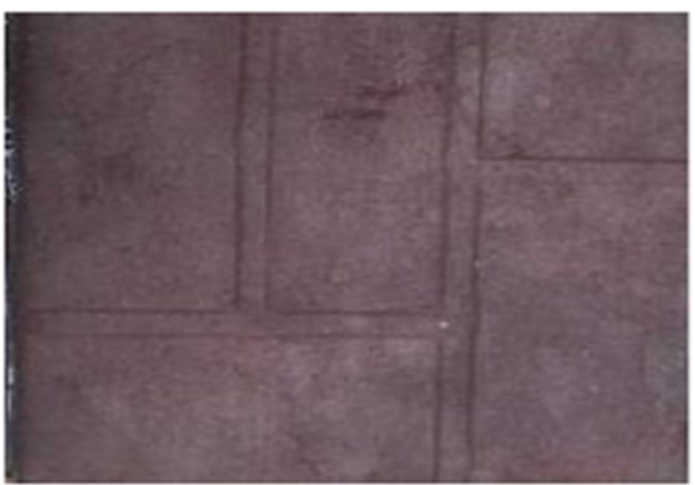


Fig. 2 Affordable Housing unit made of pet bottles and plastic waste in Nigeria [82] Source: (African Globe)

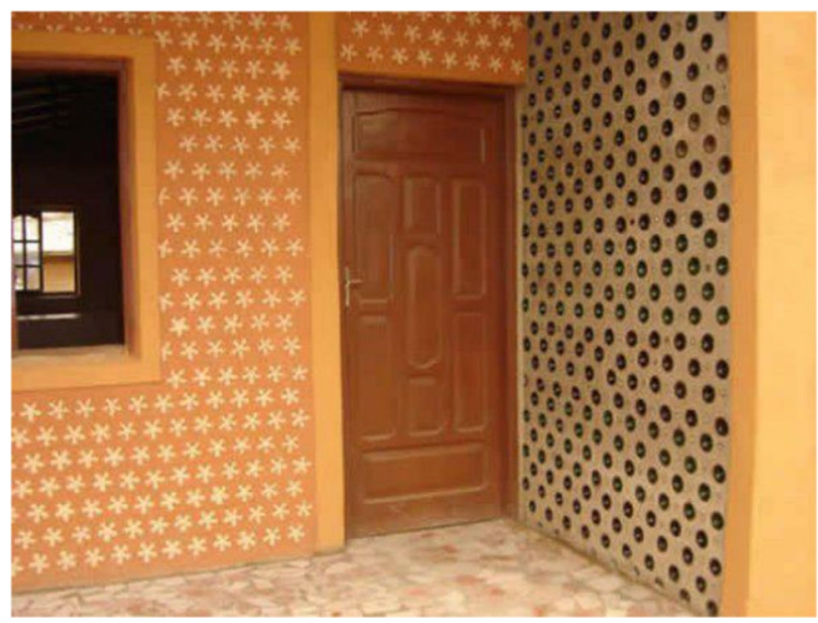

Fig. 3 Proposed process of valorisation of plastic waste into affordable housing units

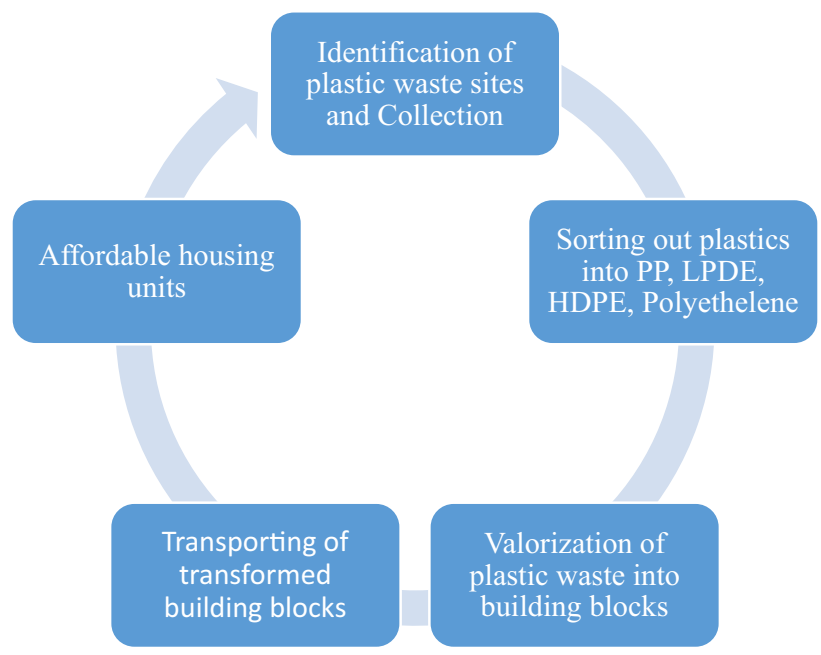

Real estate developers have purchased further land in urban centres to build luxurious buildings for the bourgeoisie and high-income earners in society [29]. This leads to a knock-off effect on the low-income earners forced into peri-urban centres and subsequently into slums [27]. With massive levels of pollution mostly attributed to improper plastic waste disposal, municipal and government policies are centred on reducing plastic waste in these areas [28]. Thus various recycling policies, especially where sorting of plastic waste is evident, these waste are converted into concrete blocks, asphalt for paving roads, among others [31]. Bricks used for housing units consist of $70 \%$ plastic waste which offers an absolute strength as opposed to laterite stones and requires less water than stone [31]. This also offers an opportunity to limit water usage in times of water crisis to increase the elasticity of water supply for domestic purposes. With the current exorbitant cost of housing units globally, the use of plastic waste for affordable housing units offers $48 \%$ cheaper prices than laterite housing units [27] (Fig. 2).

Figure 3 shows the proposed process for the valorisation of plastic waste into affordable housing units. Firstly, plastic waste hubs must be identified and subsequently collected. Some of these sites include landfills, rivers, oceans, among others. The next process is for the collected waste to be sorted out into PP, LPDE, HPDE, and polyethene. Some of these plastic waste have better stripping value and higher Marshall Value which could bind easily with bitumen and polymercoated aggregate. Also, some of these plastic waste are less susceptible to temperatures and fatigue with improved performances and better rutting resistance, especially PP. After these plastics are sorted out, the next stage is to valorise the plastic into building blocks. These valorised plastics are then transported to construction sites for constructing affordable housing units. 


\subsection{Plastic waste valorisation into fuels}

Plastic waste valorisation into fuels is essential in reducing plastic pollution globally [32]. Several alternatives to valorising plastic waste have been suggested, right from primary routes of directly recycling to quaternary routes of valorising plastics to energy [33]. The process entails converting polyolefin into valuable products, including clean fuels, naphtha (a combination of hydrocarbons), and polymers [34]. A wide range of strategies adopted include (i) gasification of plastic waste, which deals with the production of gaseous streams for energy or synthesis, (ii) pyrolysis for the production of $\mathrm{H}_{2}$ or specific pyrolysis processes, and (iii) integration of plastic derived products or plastics into refinery units [2]. There are also other forms of recycling plastic waste, but due to their inefficient nature, when there are complexities, they fail to utilise the forms or types of plastics [33]. These include the primary recycling of plastic solid waste (PSW) and mechanical recycling [34].

Mechanical recycling of plastics occurs when plastic manufacturing companies recover PSW through mechanical means, which can be done for single polymers like PS, PP, and PE [35]. The contaminated and intricate the waste is that the less it could be recycled via the mechanical process, which is most ubiquitous in African countries than in developed nations [36]. This recycling method is more ubiquitous in most African countries than in developed countries [34] compared to the chemical processes. Since the chemical process has eluded most governments in reducing recycling waste, this paper discusses them as the most efficient ways to be considered by various governments on the continent to curb the high rate of plastic pollution [37,38]. Again, there are little to no deposit policies on the continent, and therefore this process can be considered as a more efficient way to reduce plastic waste in the environment [39]. Chemical recycling [37, 38, 40,41] plays a major role in transiting circular economies and compounds like hydrocarbons and closed-loop recycling materials $[40,41]$. These systems allow for the elimination of toxic substances and, as a result, the management of difficult waste streams [38]. Chemical producers must commit to using raw materials from secondary sources to create safe, cost-effective, and viable chemical recycling supply chains [38].

Extant literature conducted on pyrolysis of plastics shows that there are four main strategies of producing fuels from plastic waste, including $\mathrm{H} 2$ production [42-47], gasification aimed at producing gaseous steam for synthesis or energy [48-53], integrating plastic wastes or plastic-derived products in refinery units [54-56], and developing specific pyrolysis process [57-66]. Based on these plethoras of literature, the findings showed that the pyrolysis process yielded a larger volume of liquid oil, of up to $80 \mathrm{wt} \%$ and with a moderate temperature of $500^{\circ} \mathrm{C}$.

Many researchers choose pyrolysis because it can yield a large volume of liquid oil, up to $80 \mathrm{wt} \%$, at a moderate temperature of $500^{\circ} \mathrm{C}$. The liquid oil produced can be used in various applications, including diesel engines, boilers, and furnaces, without further treatment or upgrading [64]. There are different compositions for plastics, which are usually stated in terms of their proximate analysis [2]. Proximate analysis is a method for determining the chemical properties of a plastic compound using four specific elements, including ash content, volatile matter, fixed carbon and moisture content, fixed carbon [63]. Findings show that the main factors that affect the liquid oil yield in the pyrolysis process are ash content and volatile matter [62]. Thus, the research showed that high volatile matter favored liquid oil production, while high ash content reduced liquid oil production, increasing gaseous yield and char formation as a result [61-65]. The volatile matter content of all plastics was found to be very high, while the ash content was found to be very low [62]. These properties mean that plastics have a high propensity for pyrolysis to contain significant amounts of liquid oil [61, 63, 65].

Using a fixed-bed reactor at $500^{\circ} \mathrm{C}$, liquid oil is generated using PET in the pyrolysis process $[67,68]$. In this experiment, the heating rate was $10 \mathrm{C} / \mathrm{min}$, and the sweeping gas was nitrogen gas. The liquid oil yield was found to be lower than the gaseous product. The liquid oil yielded was $23.1 \mathrm{wt} \%$, while the gaseous substance yielded $76.9 \%$, leaving no stable trace. The low liquid yield revealed that PET has a comparatively low volatile content of about $86.83 \%$, compared to other plastics with volatile contents of over $90 \%$ [67]. Unfortunately, the gas chromatography results-mass spectroscopy (GC-MS) study revealed that $49.93 \%$ of the oil contained benzoic acid. In another study, the liquid oil obtained was slightly higher than the previous study, with a liquid yield of $39.89 \mathrm{wt} \%$, a gaseous yield of $52.13 \mathrm{wt} \%$, and a solid residue of $8.98 \mathrm{wt} \%$ [69]. Therefore liquid oils obtained from PET ranges between 23-40 wt $\%$ and gaseous yield between $52-77 \mathrm{wt} \%$ [70].

HDPE also produces high levels of oil during pyrolysis at different operating parameters [61]. HDPE was refined into liquid oil using a pyrolysis temperature of 300-400 C and a heating rate of 5-10 C/min, with nitrogen gas as the fluidizing medium [71]. According to the experiment, the largest cumulative conversion of HDPE occurred at $350 \mathrm{C}$, with a liquid yield of $80.88 \mathrm{wt} \%$. The solid residue was very high at $300^{\circ} \mathrm{C}$ with $33.05 \mathrm{wt} \%$, but it was reduced to 0.54 
wt $\%$ at the maximum temperature of $400{ }^{\circ} \mathrm{C}$. Another experiment using a semi-batch reactor at a higher temperature range of $400-550^{\circ} \mathrm{C}$ yielded liquid oil of $79.08 \mathrm{wt} \%$ and gaseous product of $24.75 \mathrm{wt} \%$ at $550 \mathrm{C}$, while wax dominated the product fraction at temperatures of $500-550^{\circ} \mathrm{C}$. Pyrolysis yielded a dark brownish oil with no visible trace and a boiling point of 82 to $352^{\circ} \mathrm{C}$. This indicated that the oil contained various oil components, such as diesel, kerosene, and gasoline, which suited the properties of conventional petroleum. The sulfur content of the HDPE pyrolytic oil was very low at $0.019 \%$, making it environmentally friendly. Marcilla et al. [72] used a batch reactor to study HDPE pyrolysis at $550^{\circ} \mathrm{C}$ and yielded liquid oil of $84.7 \mathrm{wt} \%$ and a gaseous product of $16.3 \mathrm{wt} \%$. But when Mastral et al. [73] increased the temperature to $650^{\circ} \mathrm{C}$ in the fluidized bed reactor, it was discovered that $68.5 \mathrm{wt} \%$ liquid oil was produced and $31.5 \mathrm{wt} \%$ gaseous substance was produced. This suggests that when temperatures are increased above $550^{\circ} \mathrm{C}$, oil yields decrease.

Experiments have also been conducted on LDPE pyrolysis in a fixed-bed reactor at $500^{\circ} \mathrm{C}$ and a heat rate of $10^{\circ} \mathrm{C} / \mathrm{m}$ [74]. It lasted for $20 \mathrm{~min}$, and nitrogen was used as the fluidizing gas. It was discovered that a high liquid yield of $95 \mathrm{wt} \%$ was achieved with a low gas yield and no char. Marcilla et al. [72] also achieved a high liquid oil yield of $93.1 \mathrm{wt} \%$ when it was carried out in a batch reactor at $550{ }^{\circ} \mathrm{C}$, but with a lower heating rate of $5 \mathrm{C} / \mathrm{min}$. Again, at lower temperatures of $430^{\circ} \mathrm{C}$, Sharuddin et al. [61] obtained an oil yield of $75.6 \mathrm{wt} \%$ and Aguado et al. [75] with an oil yield of $74.7 \mathrm{wt} \%$. In another experiment, the pressure in the batch reactor was decreased to between 0.8 and $4.3 \mathrm{MPa}$ in the pyrolysis process with temperature at $450^{\circ} \mathrm{C}$, and the results showed an oil yield of $89.5 \%$ liquid oil, $10 \mathrm{wt} \%$ gaseous, and $0.5 \mathrm{wt} \%$ char [76]. This suggests that pressure has an effect on the pyrolysis of oil products.

PP pyrolysis was carried out in a micro steel reactor at temperatures ranging from 250 to $400{ }^{\circ} \mathrm{C}$ which yielded liquid oil of $69.82 \mathrm{wt} \%$ occurring at $300{ }^{\circ} \mathrm{C}$ and a cumulative conversion of $98.66 \%$ [71]. The rise in temperature to $400{ }^{\circ} \mathrm{C}$ only decreased overall substance conversion to $94.3 \%$ and increased solid residue from 1.34 to $5.7 \mathrm{wt} \%$ [71], implying that coke formation took over at higher temperatures. However, PP pyrolysis was investigated at a higher temperature of $380^{\circ} \mathrm{C}$ in another experiment [61]. They discovered a higher liquid yield of $80.1 \mathrm{wt} \%, 6.6 \mathrm{wt} \%$ gaseous residue, and $13.3 \mathrm{wt} \%$ solid residue. When temperatures was increased further by Fakhrhoseini and Dastanian [70] a higher liquid yield of around $82.12 \mathrm{wt} \%$ was obtained but increasing temperatures above $500^{\circ} \mathrm{C}$ only decreased the liquid yield obtained [77]. This was seen in the experiment of Demirbas [77], who obtained liquid oil at carried out $48.8 \mathrm{wt} \%, 49.6 \mathrm{wt} \%$ gaseous yield, and $1.6 \mathrm{wt} \%$ char at an intense temperature of $740^{\circ} \mathrm{C}$.

PS pyrolysis was carried out in a batch pressurized autoclave reactor at $300-500^{\circ} \mathrm{C}$ for one hour at a heat rate of $10 \mathrm{C} /$ min and an experimental pressure of $0.31 \mathrm{MPa}$ to $1.6 \mathrm{MPa}$ [76]. It was discovered that at the optimum temperature of $425^{\circ} \mathrm{C}$, PS pyrolysis provided a very high liquid oil yield of about $97.0 \mathrm{wt} \%$, and just $2.5 \mathrm{wt} \%$ of the gas was extracted at its limit. Another trial, which used a fluidized bed reactor at a temperature of $450-700^{\circ} \mathrm{C}$, showed a high yield of liquid oil product [78]. At $600{ }^{\circ} \mathrm{C}$, the maximum liquid oil yielded was $98.7 \mathrm{wt} \%$. At a lower temperature of $450{ }^{\circ} \mathrm{C}$, the liquid oil produced was still considered high, at $97.6 \mathrm{wt} \%$, with a difference of $1.1 \mathrm{wt} \%$. When energy conservation was a top priority, a lower temperature was preferred because it would save cost on energy. According to a study conducted, when the PS pyrolysis was run at $581{ }^{\circ} \mathrm{C}$ in a batch reactor, the liquid oil was decreased to $89.5 \mathrm{wt} \%$ [76]. As a result, running the PS pyrolysis at temperatures higher than $500^{\circ} \mathrm{C}$ is not recommended to maximize liquid oil yield.

In most African countries where plastic waste is not separated right from production, distribution to consumption creates heterogeneous resins making separation and recycling plastic waste difficult. Therefore, there is the need to also assess past literature on mixed plastics and the level of oil or fuel they produce. Pyrolysis of mixed plastic waste obtained from German homes, which contains roughly 75\% PE, PP, and 25\% PS was used for the experiment [79]. Following the addition of chlorine, a small PVC volume of $1 \mathrm{wt} \%$ was discovered. The experiment was then carried out in a fluidized bed reactor at a temperature of $730^{\circ} \mathrm{C}$, yielding $48.4 \mathrm{wt} \%$ liquid oil. The amount of liquid oil obtained was very close to that obtained by Demirbas [77] in pyrolysis of PPs, PE and PS mixture collected from landfill, which was about $46.6 \mathrm{wt} \%$. The solid and yields, respectively, were estimated to be $2.2 \mathrm{wt} \%$ and $35 \mathrm{wt} \%$. The residual PVC in the material resulted in 4 ppm chlorine in the oil, which resulted from the remaining PVC, but the detection of $4 \mathrm{ppm}$ chlorine in oil does not distort the quality of fuels since the maximum amount of chlorine found is fuels are mostly around $10 \mathrm{ppm}$. In a bubbling fluidized bed reactor, pyrolysis of mixed plastics containing $24 \mathrm{wt} \% \mathrm{PP}, 30 \mathrm{wt} \% \mathrm{HDPE}$, and $75 \mathrm{wt} \%$ LDPE was also investigated at high temperatures of $650^{\circ} \mathrm{C}$ and $730^{\circ} \mathrm{C}$ [80]. The findings revealed a higher liquid oil content of $48 \mathrm{wt} \%$ at temperatures below $650^{\circ} \mathrm{C}$. Heavy fractions such as carbon black, wax, and heavy oil made up 52\% of the oil fraction. At temperatures of $730^{\circ} \mathrm{C}$, however, $70 \%$ of the light fraction of liquid found in the pyrolysis oil was formed, with $44 \mathrm{wt} \%$ suggesting a lighter hydrocarbon liquid and gaseous with higher temperatures. From these findings on the valorisation of plastics into fuels, mixed plastics produced lower levels of liquid oil or fuels as compared to single plastics. 
For optimum utilisation of these processes, the value chain of plastic waste needs to be segregated into homogeneous plastics to achieve efficient processing of the recycled plastic waste from the production stage to the consumption stage. This would ensure that plastics are separated, monitored, and sorted to produce suitable feeds. Apart from the pyrolysis of plastic wastes into liquid or wax products, it can also generate hydrocarbon-rich gases depending on the conditions, feed, and a heating value of 25-45 MJ/kg [57] appropriate for energy recovery. These hydrocarbons from liquid and wax products make them ideal raw materials for the refinery. Although the product's scalability is minimal compared to crude oil, its conceptual proof of serving as raw materials for the refinery is validated.

\section{Benefits and challenges of producing liquid fuels from plastic waste}

Pyrolysis, unlike recycling, does not pollute water and is called a green technology because the gaseous pyrolysis byproduct has sufficient calorific value to be reused to offset the pyrolysis plant's total energy demand [76]. Since it does not require an expensive sorting waste, handling is also much simpler and more versatile than traditional recycling methods [70]. The process adds value and increases the revenue of refinery units and companies involved in the valorisation of plastic waste into liquid fuels $[74,81]$. Also, plastic waste dissolves in the solvent, increasing its bulk density, reducing the amount of plastic waste prior to the process [57]. Separation of mixed plastic into separate parts is thought to be critical since pyrolysis of single types of plastic is frequently stated to be higher than that of mixed plastic [78-80]. Therefore, using selective dissolution makes it possible to divide mixed plastic waste into its constituent parts. This is likely since some plastics can only melt in specific solvents at specific temperatures, which is alternative to manually separating plastic waste, which requires more time than mechanical separation (for instance, certain HDPE bottles with plastic labels or caps) are made of LDPE) [77, 80].

A challenge identified is that the valorisation process produces liquid fuels on a smaller scale and requires intricate post-processing to meet commercial fuel requirements. The previous experiments suggest that the valorisation of plastic waste requires highly skilled personnel and high levels of technologies in ensuring a cleaner waste polymer. Thus, catalyst poising may occur without these necessary factors, which could be highly poisonous to the environment. Again, the findings suggest that the composition in the feed and the variable quality is a challenge in producing liquid fuels from plastic waste. Thus, other plastics like large amounts of PVC and other inorganics could affect the composition feed and the quality of fuels produced. As earlier noted, the chlorine substance of more than $10 \mathrm{ppm}$ falls below the required level of chlorine in fuels and even in petrochemical fuels, and as such, with a large amount of PVC in the composition feed could reduce the quality of the fuel produced. Onwudili et al. [76] also identified that plastic waste requires pretreatment before being used in feeds to produce fuels or oils. The high volatile nature of these plastics requires dissolution to ensure that the volarisation process is done at a higher safety measure $[78,79]$. The kinetic models and reaction data are inadequate due to limited research on them leading to several problems during the design of reactors $[74,75,77-80]$.

\section{Conclusion and recommendations}

In conclusion, the paper explored eco-friendly techniques to transform plastic waste into valuable products in a sustainable environment. The trade-offs of using plastic waste for road construction and as a component in cementitious composites were discussed. Further, the challenges and benefits of producing liquid fuels from plastic waste were also addressed. It was discovered that the conversion of polyolefin waste into a broad spectrum of valuable products lie clean fuels, naphtha (a combination of hydrocarbons), polymers, among other things. Thus the potency of this innovative technology has the impetus to reduce plastic waste on the African continent and increase the profits of refinery and recycling companies. It was also found that hand pickers play a major role in reducing plastics in Africa and provides an income-generating job for waste pickers. More so, the current urbanization level in Africa with high traffic congestions offers government and real estate developers to construct roads and buildings cementitious products made of plastic waste. Again it was observed that mixed plastics produced lower levels of liquid oils or fuels as compared to single plastics. Although the product's scalability is minimal compared to crude oil, its conceptual proof of serving as raw materials for the refinery is validated. Therefore, recycling plastic waste to liquid end-products was a sustainable way of helping the environment with beneficial economic impact on the African continent.

The study recommends the following: 
- There is a need for governments in Africa to implement policies on deposits of plastics at designated centres.

- Considering the rate of plastic waste importation on the continent, there is the need to impose huge taxes on imported plastic waste to reduce its proliferation.

- There is a need to ban single-use of plastics on the continent.

- Implement novel technologies in recycling waste into reusable products and fuels.

- Affordable housing units should be constructed with plastic waste to reduce the housing deficit and reduce the enormous financial burden in providing these facilities by the government.

- Valorisation of fuels produces smaller-scale fuels compared to crude oils and therefore there is the need to integrate plastic waste polyolefins in refinery units to produce larger amounts of fuels.

Acknowledgements The authors are thankful to the Durban University of Technology, South Africa and Punjabi University, Patiala, India, for using their available resource facilities.

Authors' contributions MOA, EKT, GTM, GD and PO contributed equally in conceptualisation, writing and revising of the manuscript. All authors read and approved the final manuscript.

Funding The author(s) received no financial support for the research, authorship, and/or publication of this article.

\section{Declarations}

Competing interests The author(s) declared no potential conflicts of interest concerning the research, authorship, and/or publication of this article.

Open Access This article is licensed under a Creative Commons Attribution 4.0 International License, which permits use, sharing, adaptation, distribution and reproduction in any medium or format, as long as you give appropriate credit to the original author(s) and the source, provide a link to the Creative Commons licence, and indicate if changes were made. The images or other third party material in this article are included in the article's Creative Commons licence, unless indicated otherwise in a credit line to the material. If material is not included in the article's Creative Commons licence and your intended use is not permitted by statutory regulation or exceeds the permitted use, you will need to obtain permission directly from the copyright holder. To view a copy of this licence, visit http://creativecommons.org/licenses/by/4.0/.

\section{References}

1. Europe P. An analysis of European plastics production, demand and waste data. Plastics-the facts; 2015.

2. Lopez G, Artetxe M, Amutio M, Bilbao J, Olazar M. Thermochemical routes for the valorisation of waste polyolefinic plastics to produce fuels and chemicals. a review. Renew Sustain Energy Rev. 2017;73:346-68.

3. Africa Impact. Plastic \& environmental sustainability programs in Africa; 2020. https://www.africanimpact.com/plastic-environmentalsustainability-programs-africa/ Accessed 1 July 2020.

4. Babayemi JO, Nnorom IC, Osibanjo O, Weber R. Ensuring sustainability in plastics use in Africa: consumption, waste generation, and projections. Environ Sci Eur. 2019;31(1):60.

5. Nguyen AT. The relationship between economic growth, energy consumption and carbon dioxide emissions: evidence from central Asia. Eurasian J Bus Econ. 2019;12(24):1-15.

6. Ritchie H, Roser M. Plastic pollution. Our World Data: Oxford; 2019; 2019. https://ourworldindata.org/plastic-pollution. Accessed 14 June 2020.

7. Geyer R, Jambeck JR, Law KL. Production, use, and fate of all plastics ever made. Sci Adv. 2017;3(7):e1700782.

8. GIA (Global Industry Analysis). Plastic additives: a global strategic business report (MCP-2122, GIA); 2008. https://www.strategyr.com/ Plastic_Additives_Market_Report.asp. Accessed 1 July 2020.

9. EUROMAP. Plastics resin production and consumption in 63 countries worldwide; 2016 . http://www.pagder.org/images/files/euromappre view.pdf. Accessed 12 Aug 2019; Accessed 1 July 2020.

10. Collings J. Mind over matter: the Sasol story: a half-century of technological innovation. Johannesburg: Sasol; 2002.

11. Rajaram S. Plastic additives: the global market (PLS022B, BCC Research); 2009. https://www.bccresearch.com/market-research/plastics/ plastic-additives-market-pls022b.html. Accessed 1 July 2020.

12. Quartey ET, Tosefa H, Danquah KAB, Obrsalova I. Theoretical framework for plastic waste management in Ghana through extended producer responsibility: case of sachet water waste. Int J Environ Res Public Health. 2015;12(8):9907-19.

13. Nyarko AD, Adu KJ. Impact of sachet water and plastic bottle waste on agricultural land in the Ada East District of Ghana. Asian Res J Agric. 2016. https://doi.org/10.9734/ARJA/2016/28461.

14. Association of African Entrepreneurs. Remove, reduce, and recycle-the waste nylon sachet water in Nigeria; 2017. http://www.aaeaf rica.org/home/remove-reduce-recycle-waste-nylon-sachet-water-nigeria/. Accessed 1 July 2020.

15. Schenck CJ, Blaauw PF, Viljoen JM, Swart EC. Exploring the potential health risks faced by waste pickers on landfills in South Africa: a socio-ecological perspective. Int J Environ Res Public Health. 2019;16(11):2059. 
16. Schenck R, Blaauw PF. The work and lives of street waste pickers in Pretoria-a case study of recycling in South Africa's urban informal economy. In: Urban Forum, vol. 22, no. 4. Dordrecht: Springer; 2011, p. 411.

17. Godfrey L, Oelofse S. Historical review of waste management and recycling in South Africa. Resources. $2017 ; 6(4): 57$.

18. Appiah JK, Berko-Boateng VN, Tagbor TA. Use of waste plastic materials for road construction in Ghana. Case Stud Constr Mater. 2017;6:1-7.

19. Bale AS. Potential reuse of plastic waste in road construction: a review. Int J Adv Eng Technol IJAET. 2011;2:233-6.

20. Vasudevan R, Sekar ARC, Sundarakannan B, Velkennedy R. A technique to dispose waste plastics in an ecofriendly way-application in construction of flexible pavements. Constr Build Mater. 2012;28(1):311-20.

21. Zhao Z, Xiao F, Amirkhanian S. Recent applications of waste solid materials in pavement engineering. Waste Manage. 2020;108:78-105.

22. Ahmedzade P, Fainleib A, Günay T, Grygoryeva O. Modification of bitumen by electron beam irradiated recycled low density polyethylene. Constr Build Mater. 2014;69:1-9.

23. Ahmedzade P, Günay T, Grigoryeva O, Starostenko O. Irradiated recycled high density polyethylene usage as a modifier for bitumen. J Mater Civ Eng. 2017;29(3):04016233.

24. Choudhary AK, Jha JN, Gill KS, Shukla SK. Utilization of fly ash and waste recycled product reinforced with plastic wastes as construction materials in flexible pavement. In: Geo-congress 2014: geo-characterization and modeling for sustainability; 2014 . p. 3890-902.

25. García-Travé G, Tauste R, Moreno-Navarro F, Sol-Sánchez M, Rubio-Gámez MC. Use of reclaimed geomembranes for modification of mechanical performance of bituminous binders. J Mater Civ Eng. 2016;28(7):04016021.

26. Padhan RK, Sreeram A. Enhancement of storage stability and rheological properties of polyethylene (PE) modified asphalt using cross linking and reactive polymer based additives. Constr Build Mater. 2018;188:772-80.

27. Allam Z, Jones DS. Towards a circular economy: a case study of waste conversion into housing units in Cotonou. Benin Urban Science. 2018;2(4):118.

28. Tam VW, Tam CM. A review on the viable technology for construction waste recycling. Resour Conserv Recycl. 2006;47(3):209-21.

29. Jalaluddin M. Use of plastic waste in civil constructions and innovative decorative material (eco-friendly). MOJ Civ Eng. 2017;3(05):01-10.

30. Goli VSNS, Mohammad A, Singh DN. Application of municipal plastic waste as a manmade neo-construction material: issues \& wayforward. Resour Conserv Recycl. 2020;161:105008.

31. Aciu C, llutiu-Varvara DA, Manea DL, Orban YA, Babota F. Recycling of plastic waste materials in the composition of ecological mortars. Proc Manuf. 2018;22:274-9.

32. Hahladakis JN, Velis CA, Weber R, lacovidou E, Purnell P. An overview of chemical additives present in plastics: migration, release, fate and environmental impact during their use, disposal and recycling. J Hazard Mater. 2018;344:179-99.

33. Chancerel P, Rotter S. Recycling-oriented characterisation of small waste electrical and electronic equipment. Waste Manage. 2009;29(8):2336-52.

34. Kaiser K, Schmid M, Schlummer M. Recycling of polymer-based multilayer packaging: a review. Recycling. 2018;3(1):1.

35. UNEP. Plastic and toxic additives, and the circular economy: the role of the Basel and Stockholm Conventions; 2019. http://www.UNEP/ CHW.14/INF/29/Add.1-UNEP/POPS/COP.9/INF/28/Add.1. Accessed 1 July 2020.

36. Fineberg,H. Reinventing Plastics, s.I. Available at: Institut Veolia; 2019. https://www.institut.veolia.org/en/nos-publications/la-revue-delinstitut-facts-reports/reinventing-plastics Accessed 1 July 2020.

37. Grause G, Buekens A, Sakata Y, Okuwaki A, Yoshioka T. Feedstock recycling of waste polymeric material. J Mater Cycles Waste Manage. 2011;13(4):265-82.

38. Qureshi MS, Oasmaa A, Pihkola H, Deviatkin I, Tenhunen A, Mannila J, Laine-Ylijoki J. Pyrolysis of plastic waste: opportunities and challenges. J Anal Appl Pyrol. 2020;152:104804.

39. Ocean Recovery Alliance (ORA). Plastics-to-fuel project developer's guide; 2015. https://www.oceanrecov.org/assets/files/Valuing_Plast ic/2015-PTFProject-Developers-Guide.pdf. Accessed 1 July 2020.

40. Scheirs J, Kaminsky W, editors. Feedstock recycling and pyrolysis of waste plastics. Chichester: John Wiley \& Sons; 2006. p. $383-434$.

41. Ruban M, Ramasubramanian S, Pugazhenthi R. Investigation of performance analysis and emission characteristics of waste plastic fuel. In: IOP conference series: materials science and engineering, vol. 183, no. 1. Bristol: IOP Publishing; 2017, p. 012037.

42. Erkiaga A, Lopez G, Barbarias I, Artetxe M, Amutio M, Bilbao J, Olazar M. HDPE pyrolysis-steam reforming in a tandem spouted bed-fixed bed reactor for $\mathrm{H} 2$ production. J Anal Appl Pyrol. 2015;116:34-41.

43. Saad JM, Nahil MA, Williams PT. Influence of process conditions on syngas production from the thermal processing of waste high density polyethylene. J Anal Appl Pyrol. 2015;113:35-40.

44. Namioka T, Saito A, Inoue Y, Park Y, Min TJ, Roh SA, Yoshikawa K. Hydrogen-rich gas production from waste plastics by pyrolysis and lowtemperature steam reforming over a ruthenium catalyst. Appl Energy. 2011;88(6):2019-26.

45. Barbarias I, Lopez G, Alvarez J, Artetxe M, Arregi A, Bilbao J, Olazar M. A sequential process for hydrogen production based on continuous HDPE fast pyrolysis and in-line steam reforming. Chem Eng J. 2016;296:191-8.

46. Wu C, Williams PT. A novel Ni-Mg-Al-CaO catalyst with the dual functions of catalysis and $\mathrm{CO} 2$ sorption for $\mathrm{H} 2$ production from the pyrolysis-gasification of polypropylene. Fuel. 2010;89(7):1435-41.

47. Barbarias I, Lopez G, Artetxe M, Arregi A, Santamaria L, Bilbao J, Olazar M. Pyrolysis and in-line catalytic steam reforming of polystyrene through a two-step reaction system. J Anal Appl Pyrol. 2016;122:502-10.

48. Wilk V, Hofbauer H. Conversion of mixed plastic wastes in a dual fluidized bed steam gasifier. Fuel. 2013;107:787-99.

49. Arena U, Di Gregorio F. Energy generation by air gasification of two industrial plastic wastes in a pilot scale fluidized bed reactor. Energy. 2014;68:735-43.

50. Erkiaga A, Lopez G, Amutio M, Bilbao J, Olazar M. Syngas from steam gasification of polyethylene in a conical spouted bed reactor. Fuel. 2013;109:461-9.

51. Toledo JM, Aznar MP, Sancho JA. Catalytic air gasification of plastic waste (polypropylene) in a fluidized bed. Part II: effects of some operating variables on the quality of the raw gas produced using olivine as the in-bed material. Ind Eng Chem Res. 2011;50(21):11815-21.

52. Sancho JA, Aznar MP, Toledo JM. Catalytic air gasification of plastic waste (polypropylene) in fluidized bed. Part l: use of in-gasifier bed additives. Ind Eng Chem Res. 2008;47(4):1005-10. 
53. Kim JW, Mun TY, Kim JO, Kim JS. Air gasification of mixed plastic wastes using a two-stage gasifier for the production of producer gas with low tar and a high caloric value. Fuel. 2011;90(6):2266-72.

54. Arandes JM, Abajo I, Lopez-Valerio D, Fernández I, Azkoiti MJ, Olazar M, Bilbao J. Transformation of several plastic wastes into fuels by catalytic cracking. Ind Eng Chem Res. 1997;36(11):4523-9.

55. Ucar S, Karagöz S, Karayildirim T, Yanik J. Conversion of polymers to fuels in a refinery stream. Polym Degrad Stab. 2002;75(1):161-71.

56. Arandes JM, Torre I, Castano P, Olazar M, Bilbao J. Catalytic cracking of waxes produced by the fast pyrolysis of polyolefins. Energy Fuels. 2007;21(2):561-9.

57. Wong SL, Ngadi N, Abdullah TAT, Inuwa IM. Current state and future prospects of plastic waste as source of fuel: a review. Renew Sustain Energy Rev. 2015;50:1167-80.

58. Aguado J, Serrano DP, Escola JM. Fuels from waste plastics by thermal and catalytic processes: a review. Ind Eng Chem Res. 2008;47(21):7982-92.

59. Butler E, Devlin G, McDonnell K. Waste polyolefins to liquid fuels via pyrolysis: review of commercial state-of-the-art and recent laboratory research. Waste Biomass valoriz. 2011;2(3):227-55.

60. Miandad R, Barakat MA, Aburiazaiza AS, Rehan M, Nizami AS. Catalytic pyrolysis of plastic waste: a review. Process Saf Environ Prot. 2016;102:822-38.

61. Sharuddin SDA, Abnisa F, Daud WMAW, Aroua MK. A review on pyrolysis of plastic wastes. Energy Convers Manage. 2016;115:308-26.

62. Kunwar B, Cheng HN, Chandrashekaran SR, Sharma BK. Plastics to fuel: a review. Renew Sustain Energy Rev. 2016;54:421-8.

63. Ma C, Yu J, Wang B, Song Z, Xiang J, Hu S, et al. Chemical recycling of brominated flame retarded plastics from e-waste for clean fuels production: a review. Renew Sustain Energy Rev. 2016;61:433-50.

64. Hita I, Arabiourrutia M, Olazar M, Bilbao J, Arandes JM, Castaño P. Opportunities and barriers for producing high quality fuels from the pyrolysis of scrap tires. Renew Sustain Energy Rev. 2016;56:745-59.

65. Serrano DP, Aguado J, Escola JM. Developing advanced catalysts for the conversion of polyolefinic waste plastics into fuels and chemicals. ACS Catal. 2012;2(9):1924-41.

66. Baytekin B, Baytekin HT, Grzybowski BA. Retrieving and converting energy from polymers: deployable technologies and emerging concepts. Energy Environ Sci. 2013;6(12):3467-82.

67. Çepelioğullar Ö, Pütün AE. Utilization of two different types of plastic wastes from daily and industrial life. J Selcuk Univ Nat Appl Sci. 2013;2(2):694-706.

68. Wan Ho M. Waste plastics into fuel oil. Nottingham: Institute of Science in Society; 2015.

69. Shioya M. Development of waste plastics liquefaction technology, feedstock recycle in Japan. In: Proceedings of the third international symposium of feedstock recycling of plastics and other innovative plastics recycling techniques. Karlsruhe, Germany, Sept. 25-28, 2005; 2005.

70. FakhrHoseini SM, Dastanian M. Predicting pyrolysis products of PE, PP, and PET using NRTL activity coefficient model. J Chem. 2013. https://doi.org/10.1155/2013/487676.

71. Ahmad I, Khan MI, Khan H, Ishaq M, Tariq R, Gul K, Ahmad W. Pyrolysis study of polypropylene and polyethylene into premium oil products. Int J Green Energy. 2015;12(7):663-71.

72. Marcilla A, Beltrán MI, Navarro R. Thermal and catalytic pyrolysis of polyethylene over HZSM5 and HUSY zeolites in a batch reactor under dynamic conditions. Appl Catal B. 2009;86(1-2):78-86.

73. Mastral FJ, Esperanza E, Garcia P, Juste M. Pyrolysis of high-density polyethylene in a fluidised bed reactor. Influence of the temperature and residence time. J Anal Appl Pyrol. 2002;63(1):1-15.

74. Bagri R, Williams PT. Catalytic pyrolysis of polyethylene. J Anal Appl Pyrol. 2002;63(1):29-41.

75. Aguado J, Serrano DP, San Miguel G, Castro MC, Madrid S. Feedstock recycling of polyethylene in a two-step thermo-catalytic reaction system. J Anal Appl Pyrol. 2007;79(1-2):415-23.

76. Onwudili JA, Insura N, Williams PT. Composition of products from the pyrolysis of polyethylene and polystyrene in a closed batch reactor: effects of temperature and residence time. J Anal Appl Pyrol. 2009;86(2):293-303.

77. Demirbas A. Pyrolysis of municipal plastic wastes for recovery of gasoline-range hydrocarbons. J Anal Appl Pyrol. 2004;72(1):97-102.

78. Liu Y, Qian J, Wang J. Pyrolysis of polystyrene waste in a fluidized-bed reactor to obtain styrene monomer and gasoline fraction. Fuel Process Technol. 2000;63(1):45-55.

79. Kaminsky W, Schlesselmann B, Simon CM. Thermal degradation of mixed plastic waste to aromatics and gas. Polym Degrad Stab. 1996;53(2):189-97.

80. Donaj PJ, Kaminsky W, Buzeto F, Yang W. Pyrolysis of polyolefins for increasing the yield of monomers' recovery. Waste Manage. 2012;32(5):840-6.

81. Kumar S, Singh RK. Recovery of hydrocarbon liquid from waste high density polyethylene by thermal pyrolysis. Braz J Chem Eng. 2011;28(4):659-67.

82. Akinwumi II, Domo-Spiff AH, Salami A. Marine plastic pollution and affordable housing challenge: Shredded waste plastic stabilized soil for producing compressed earth bricks. Case Stud Constr Mater. 2019;11:e00241.

Publisher's Note Springer Nature remains neutral with regard to jurisdictional claims in published maps and institutional affiliations. 